\title{
Cognitive Functions and Health Related Quality of Life of Institutional Autism Spectrum Disorder Children in Dhaka city
}

\author{
Jahan $\mathrm{MU}^{1}$, Karim $\mathrm{MR}^{2}$, Rahman $\mathrm{A}^{3}$, Akhter $\mathrm{S}^{4}$ \\ ${ }^{1}$ Consultant Rodiologist, ${ }^{2}$ Epidemiology OSD, Directorate General of Health Services, Mohakhali, Dhaka. \\ ${ }^{3}$ Epidemiology, National Institute of Preventive and Social Medicine, Mohakhali, Dhaka. ${ }^{4}$ Gynaecologist, Lt \\ Colonel, Army Medical Core, Comilla Cantonment. \\ Email: riponjahan@yahoo.com
}

\begin{abstract}
In Bangladesh, nearly 10.5 hundred thousand individuals may have autism. Recent figures released by the CDC (2012) show that autism spectrum disorders (ASDs) now affect 1 in 88 children. Cognitive impairment, limited adaptive skills, and severe social impairment as seen in Autism Spectrum Disorders (ASD) thought to be associated with poorer health related quality of life (HRQoL). The objective of the study was to measure HRQoL and cognitive functioning in a group of autism Spectrum Disorder (ASD) children and to relate HRQoL with their socio demographic characteristics and cognitive functioning from parents' perception.
\end{abstract}

This cross sectional study was conducted among149 purposively selected parents who have institutionalized autistic children ( 2 to 18 years old) from January to June 2013. HRQoL was assessed by Pediatric Quality of Life Inventory 4.0 (Verni1998) and cognitive functioning was assessed with The PedsQL TM Cognitive Functioning Scale.

Three fourth of the children were male $(\mathrm{n}=115,77.2 \%)$ and the mean (SD) age of the children was 7.8(3.06) years. Symptoms of autism appeared at about their 2nd birthday 2.1 (.70) while the average (SD) age of diagnosis was around three years 2.9 (.98). The children were reported to go to school at an early age of 3(1.75) years. Out of 149 respondents, ten percent parents $(n=14)$ had the history of consanguineous marriage.

The sample data provides significant difference between the scores by the ability of verbal communication $(\mathrm{p}<.05)$, presence of autistic siblings $(\mathrm{p}<.05)$ and mother's occupation $(\mathrm{p}<.05)$. There found negative correlation between HRQoL and age of symptom appearance and cognitive functioning with age of diagnosis $(\mathrm{r}=-0.18 ; \mathrm{p}=.03)$. Cognitive functioning was strongly correlated with total PedsQL score and its domains $(r=0.73 ; \mathrm{p}=.00)$. i.e. Higher cognitive function leads to good health related quality of life. Linear regression was performed to study the relationship between HRQoL and independent variables found significant in univariate analysis. The results of the regression indicated the predictors in the model explained $57 \%$ of the variance $(\mathrm{R} 2=.57, \mathrm{~F}=23.05, \mathrm{p}<.001)$. It was found that fathers who were doctors and engineers by profession ( $\mathrm{t}=2.34, \mathrm{p}=.02)$, child's ability to communicate with words $(\mathrm{t}=2.73, \mathrm{p}=.007)$, age of symptom appearance $(\mathrm{t}=-2.71, \mathrm{p}=.008)$, and cognitive functioning $(\mathrm{t}=12.28, \mathrm{p}<0.001)$ significantly predicted HRQol of ASD children.

Father's occupational status, child's ability to communicate by word, age of symptom appearance, and Cognitive functioning of ASD children were found related to their quality of life.

Key word: Autism Spectrum Disorder (ASD), Health Related Quality of Life (HRQoL), Cognitive Functioning, Pediatric Quality of Life (PedsQL) scale.

\section{Introduction}

Autism Spectrum Disorders (ASD) are cognitive and neurobehavioral disorders, having three core features: deficits in socialization, deficits in verbal \& nonverbal communication and restricted and repetitive patterns of behaviours. ${ }^{1}$ HealthRelated Quality of Life (HRQoL) is a comprehensive approach to measure health outcomes which is a subjective term that 
emphasizes happiness and overall wellbeing as they relate to conditions that have a multidimensional impact, such as Autism Spectrum Disorders (ASD). ${ }^{2}$ In Bangladesh, nearly 10.5 hundred thousand individuals may have autism. ${ }^{3}$ In the Institution for Paediatric Neuro-disorders and Autism (IPNA), at Bangabandhu Sheikh Mujib Medical University only 12 children attended with autism in the year 2001, which increased to 105 children in 2009 suggesting increase in prevalence, more awareness amongst parents and probably improvement in screening and diagnosis of autism spectrum disorder. ${ }^{3}$

ASDs regularly experience severe difficulties especially in interpersonal relationships and often appear as solitary in their familial and social milieu. HRQoL was found lower among children with ASD and psychotropic medications often contribute some extra score to make it better. HRQoL was also found correlated with severity of disorder and the age that the first signs appeared. ${ }^{4}$ Furthermore, recent studies confirm, that higher cognitive scores do not necessarily reflect better adaptive skill in children with ASD, thus leading to considerable impairment in everyday life. ${ }^{5}$ Over one third of children with

ASD have some comorbid ADHD (attention deficit hyperactivity disorder) symptoms, and that the presence of ADHD symptoms is related to greater problems in adaptive skills and poorer overall HRQoL. ${ }^{6}$

Age-appropriateness and population specificity, multidimensionality are key issues to predict $\mathrm{QoL}$ reliably. For example, a child may enjoy a high level family functioning but his school functioning stays stumpy. Thus, the child's overall QoL may not accurately portray the level of overall subjective well-being. ${ }^{7}$ In addition, parent proxy and children's self -assessment showed poor agreement suggesting that they were counting different aspects of HRQoL. The possible reasons for these differences were pointed to parental stress and quality of the parent-child relationship. ${ }^{8,9}$ The PedsQL (Pediatric Quality of Life Inventory) 4.0; Verni1998, is a modular instrument for ensuring health- related quality of life (HRQoL) and the PedsQLTM cognitive functioning scale has been utilized across numerous paediatric chronic conditions. 10
Studies revealed quality of living and cognitive functioning of the children having ASD depends on various parental and ASD related characteristics. ASD related characteristics like schooling, verbal communication, taking any other medication, formal education also has effect on the quality of life and cognitive development of autistic children. Although limited studies related to HRQoL of children with ASD has been conducted in our country, it is shown that these associations would be particularly strong for aspects of

HRQoL related to psychosocial health rather than physical health and children with higher levels of total behavior problems would have poorer HRQoL. ${ }^{11-14}$

The objective of the study was to measure HRQoL and cognitive functioning in a group of institutional children with ASD in Dhaka city, to relate HRQoL with socio demographic characteristics of ASD, and analyse the relationships between HRQoL and cognitive functioning of these children from parents' perception.

\section{Materials and Methods}

This cross sectional study was conducted to assess health related quality of life and cognitive functioning from the perspective of parents of purposively selected 2-18 years old school aged autistic children from January to June 2014. Assuming 95\% confidence and $80 \%$ power, and observing a HRQoL mean of 66.40 and standard deviation 20.00 from literature review 2, the estimated sample size was 142 (using sample power IBM). Enrollment of 149 respondents from five specialized institutions of Dhaka city for the purpose. Simple random sampling technique was employed. The school registers served as sampling frame. Researcher enrolled 149 mothers from five specialized schools (Proyash, School for Gifted Children-lalmatia, Alokito Sishu Mohammadpur, AWF -Mohammadpur, Kids Care -Banani) of Dhaka city within the data collection period. After selecting cases from the school register, an informed letter was also issued from the principal of the institute to the mothers of the autistic child in the conference hall of the school where they were requested to participate in the study by informing about the objective of the 
study in detail and briefing them about the contents of the questionnaire.

A total of 236 mothers were requested to give consent for face to face interview, off whom 149 agreed to participate in the study. Data were collected by face to face interview with a semistructured questionnaire. Cases were excluded on refusal to take participate in the current study. Ethical approval for the study was provided by the Bangladesh medical and Research Council, Mohakhali, Dhaka.

\section{Data Collection Instrument}

\section{Pediatric Quality of Life Inventory 4.0:}

Pediatric Quality of Life Inventory 4.0 (PedsQL) (Varni 1998), is a 23-item questionnaire designed to assess children 2- 18 years old. The PedsQL includes four a ge appropriate versions and takes approximately 7-10 min to complete. The PedsQLTM 4.0 Generic Core Scales are comprised of parallel child self-report and parent proxy-report formats. Parent proxy-report includes ages 2-4 (toddler), 5-7 (young child), 812 (child), and 13-18 (adolescent), years and assesses parents' perceptions of their children's HRQOL. The items for each of the forms are essentially identical, differing in developmentally appropriate language, or first or third person tense. The instructions ask how much of a problem each item has been during the past 1 month. A 5-point Likert scale is utilized across child self-report for ages $8-18$ years and parent prox y-report $(0=$ never a problem; $1=$ almost never a problem; $2=$ sometimes a problem; $3=$ often a problem; $4=$ almost always a problem). Only parent proxy report data for children 6-12 years were collected and utilized for the present study. Items are reverse-scored and linearly transformed to a 0 100 scale $(0=100,1=75,2=50,3=25,4=0)$, so that higher scores indicate better HRQoL. Scale Scores are computed as the sum of the items divided by the number of items answered (this accounts for missing data). If more than $50 \%$ of the items in the scale are missing, the Scale Score is not computed. The Physical Health Summary Score ( 8 items) is the same as the physical Functioning Scale. To create the Psychosocial Health Summary Score (15 items), the mean is computed as the sum of the items divided by the number of items answered in the Emotional, Social, and School Functioning Scales. The School Functioning Summary Score (5 items) is the same as the School Functioning Scale. As demonstrated in the initial field test of the PedsQLTM 4.0 Generic Core Scales 14, and subsequent investigations 10 , two constructs are being measured by the School Functioning Scale (3-item school-related cognitive functioning scale and a 2-item school- related days' missed scale).

PedsQL-4.0 cognitive functioning scale:

The PedsQLTM Cognitive Functioning Scale includes 6 items. Child self-report includes ages $5-7,8-12$, and $13-18$ years. Parent proxy-report includes ages 2-4 (toddler), 5-7 (young child), 812 (child), and 13-18 (adolescent) years, and assesses parents' perceptions of their children's cognitive functioning. For the purposes of the present study, we utilized only the parent proxyreport version. The format, instructions, Likert scale, and scoring method are identical to the PedsQLTM 4.0 Generic Core Scales, with higher scores indicating better HRQoL (fewer cognitive problems).

\section{Statistical analysis:}

Data were entered, cleaned, edited and analysed using SPSS for windows version 20. Categorical data were described as frequency and percentages and quantitative data were stated with mean (SD), median (interquartile range). We compared the difference in scores by ASD sample data applying Student's t test and One Way ANOVA. The direction, degree and form of relationship of Quantitative variables were assessed by Pearson Product Moment Correlation Coefficient. Multiple regression analysis was performed to predict the important factors related to HRQol. The variables showed $\mathrm{p}$ value less than .2 in univariate analysis were included in multiple regression analysis model and reported with $\mathrm{t}$ statistic, $\beta$ (beta co-efficient); $95 \% \mathrm{CI}$ for $\beta$ and $\mathrm{p}$ value. $\mathrm{F}$ statistic and model $\mathrm{R}^{2}$ were also reported.

\section{Result}

The socio-demographic characteristics were presented in table I. Out of 149 children, three fourth $(n=115,77.2 \%)$ were male and the same proportion $(n=113,75.8 \%)$ hailed from nuclear family. They were mostly $(n=135,90.6 \%)$ within twelve years of age with a mean (SD) age of 7.8(3.06) years. Sample data showed the average (SD) age of symptom appearance was two years 


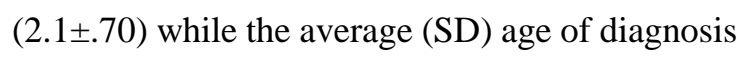

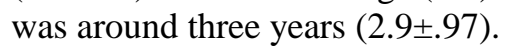

Table I: Socio-demographic characteristics and ASD related characteristics $(\mathrm{n}=149)$

\begin{tabular}{|c|c|c|}
\hline Socio-Demographic & $\mathbf{f}_{\mathrm{i}}$ & $\%$ \\
\hline \multicolumn{3}{|l|}{ Age group } \\
\hline Less than 6 yrs & 50 & 33.6 \\
\hline $6-12 \mathrm{yrs}$ & 85 & 57.0 \\
\hline $12-18 \mathrm{yrs}$ & 14 & 9.4 \\
\hline \multicolumn{3}{|l|}{ Gender } \\
\hline Male & 115 & 77.2 \\
\hline Female & 34 & 22.8 \\
\hline \multicolumn{3}{|l|}{ Consanguineous marriage } \\
\hline No & 135 & 90.6 \\
\hline Yes & 14 & 9.4 \\
\hline \multicolumn{3}{|l|}{ Education of mother } \\
\hline Illiterate, Primary to secondary & 9 & 6.0 \\
\hline Higher Secondary & 19 & 12.8 \\
\hline Degree/ Hon's and others & 121 & 81.2 \\
\hline \multicolumn{3}{|l|}{ Education of father } \\
\hline Illiterate Primary to higher secondary & 11 & 7.4 \\
\hline Degree/ Hon's and others & 138 & 92.6 \\
\hline \multicolumn{3}{|l|}{ Father's occupation } \\
\hline Unemployed, Business and others & 39 & 26.2 \\
\hline Teacher, Doctor and Engineer & 33 & 22.1 \\
\hline Service & 77 & 51.7 \\
\hline \multicolumn{3}{|l|}{ Mother's occupation } \\
\hline Unemployed, Business and others & 51 & 34.2 \\
\hline Teacher, Doctor and Engineer & 21 & 14.1 \\
\hline Service & 77 & 51.7 \\
\hline \multicolumn{3}{|l|}{ Type of Family } \\
\hline Nuclear & 113 & 75.8 \\
\hline Joint & 36 & 24.2 \\
\hline \multicolumn{3}{|l|}{ ASD related characteristics } \\
\hline \multicolumn{3}{|l|}{ Communication } \\
\hline Non-verbal & 75 & 50.3 \\
\hline Verbal with words & 35 & 23.5 \\
\hline Can speak sentence & 39 & 26.2 \\
\hline \multicolumn{3}{|l|}{ Presence of autism in siblings } \\
\hline Not affected & 139 & 93.3 \\
\hline Affected & 10 & 6.7 \\
\hline \multicolumn{3}{|l|}{ Vaccination } \\
\hline Incomplete & 12 & 8.1 \\
\hline Complete & 137 & 91.9 \\
\hline \multicolumn{3}{|l|}{ Formal Education } \\
\hline Yes & 56 & 37.6 \\
\hline No & 93 & 62.4 \\
\hline \multicolumn{3}{|l|}{ Schooling } \\
\hline For 4 years & 94 & 63.1 \\
\hline For $4-8$ years & 55 & 36.9 \\
\hline \multicolumn{3}{|l|}{ Take any other medicine } \\
\hline No & 97 & 65.1 \\
\hline Yes & 52 & 34.9 \\
\hline
\end{tabular}

One out of ten respondents $(n=14,9.4 \%)$ had a history of consanguineous marriage. Regarding educational status of the parents, most of the mothers $(n=140,93 \%)$ were found educated up to higher secondary level and most of the fathers $(n=138,92.6 \%)$ were found completed their graduation. In case of occupational status $14 \%$ $(n=21)$ mothers and 22\% $(n=33)$ fathers were skilled professionals, eg. teacher, doctor and engineer. Sample data showed that fifty percent $(\mathrm{n}=75,50.3 \%)$ of ASD children could not communicate verbally although a higher proportion $(n=94,63.1 \%)$ of children were found to go to school for 4 years. More than ninety percent $(n=139,93.3 \%)$ of the children's siblings were not affected by autism.

Figure 1 shows the mean scores for the total HRQoL and its domains. Among all domains physical functioning scored the highest (77.2 \pm 19.38 ) followed by school functioning (72.91 \pm 19.16$)$, psychosocial functioning $(68.27 \pm 17.79)$, social $(66.74 \pm 24.36)$ and emotional functioning $(65.16 \pm 18.44)$. (Figure1). The mean (SD) score for total HRQoL and cognitive functioning was $(71.38 \pm 16.76)$ and

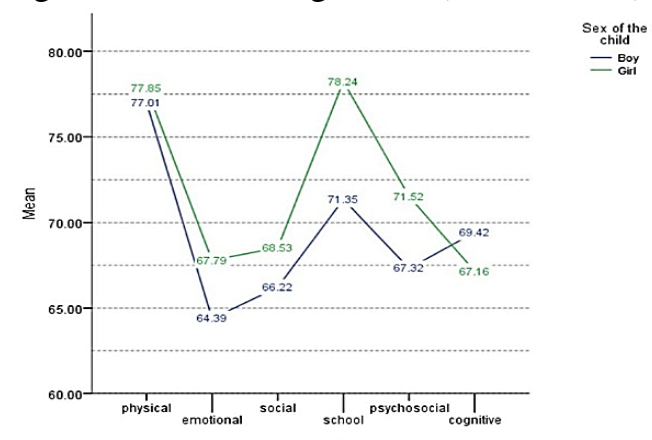

Fig 1. HRQOL subscales and cognitive Functioning mean scores by sex of the child $(68.90 \pm 23.40)$ respectively.

The differences of average (SD) of HRQoL scores and cognitive functioning scores were examined against the socio-demographic and disease related characteristics of sample children, which revealed no statistical significance $(\mathrm{p} \geq 0.05)$ in the mean (SD) scores between male and female although total HRQoL was better in female $(73.72 \pm 16.7)$ and the cognitive functioning was better in male (69.42 \pm 23.6$)$. There were observed no significant differences between the scores by gender, status of formal education, vaccination, taking any other medicine, type of family, mother's education, father's education and consanguineous marriage ( $>>0.05)$.

The analysis showed statistically significant difference $(p<0.05)$ between the scores of physical functioning, total HRQoL and school functioning for verbal communication $(p<.05)$. Moreover, those children with autism in siblings had statistically significant difference in the score of physical functioning and school functioning $(p<0.05)$. Lastly, there were statistically significant difference between the mean scores of social functioning and psychosocial functioning with mother's occupation $(\mathrm{p}<.05)$. (Table II) 
Table II: HRQoL, and Cognitive functioning summary scores by demographic and disease related variables

\begin{tabular}{|c|c|c|c|c|c|c|c|}
\hline Parents proxy & Total & Physical & Emotional & Social & School & Psychosocial & Cognitive \\
\hline \multicolumn{8}{|l|}{ Gender } \\
\hline Male & $70.69(16.8)$ & $77.01(20.14)$ & $64.39(18.04)$ & $66.21(24.27)$ & $71.34(19.35)$ & $67.31(17.60)$ & $69.42(23.6)$ \\
\hline Female & $73.72(16.7)$ & $77.84(16.82)$ & $67.79(19.81)$ & $68.52(24.97)$ & $78.23(17.74)$ & $71.51(18.33)$ & $67.15(22.9)$ \\
\hline$p$-value & 0.35 & 0.82 & 0.34 & 0.62 & 0.06 & 0.22 & 0.62 \\
\hline \multicolumn{8}{|l|}{ Formal Education } \\
\hline No & $70.89(18.1)$ & $75.60(20.5)$ & $66.23(19.6)$ & $68.06(25.1)$ & $70.86(20.8)$ & $67.95(19.4)$ & $69.71(26.01)$ \\
\hline Yes & $72.18(14.3)$ & $79.85(17.2)$ & $63.39(16.3)$ & $64.55(13.1)$ & 76.33(15.7) & $71.42(14.9)$ & $67.55(18.4)$ \\
\hline$p$-value & .65 & .19 & .36 & .39 & .07 & .91 & .55 \\
\hline \multicolumn{8}{|l|}{ Vaccination } \\
\hline Incomplete & $75.18(11.9)$ & 83.07(13.55) & $72.50(14.7)$ & $62.08(19.0)$ & 78.33(14.6) & $70.97(13.1)$ & $70.83(21.3)$ \\
\hline Complete & $71.04(17.1)$ & $76.68(19.8)$ & $64.52(18.6)$ & $67.15(24.8)$ & 72.44(19.5) & $68.04(18.2)$ & $68.73(23.6)$ \\
\hline$p$-value & 0.41 & 0.27 & 0.15 & 0.49 & 0.30 & 0.58 & 0.76 \\
\hline \multicolumn{8}{|l|}{ Take any medicine } \\
\hline No & $71.50(14.4)$ & $78.18(17.21)$ & 64.94(16.62) & $64.63(22.29)$ & $74.22(16.74)$ & $67.93(15.56)$ & $68.98(21.73)$ \\
\hline Yes & $71.15(20.5)$ & $75.36(22.96)$ & $65.57(21.61)$ & $70.67(27.63)$ & $70.48(22.99)$ & $68.91(21.50)$ & $68.75(26.46)$ \\
\hline$p$-value & 0.91 & 0.39 & 0.85 & 0.17 & 0.30 & 0.77 & 0.95 \\
\hline \multicolumn{8}{|c|}{ Verbal communication } \\
\hline No & 67.73 & $72.37(21.23)$ & $63.40(19.95)$ & $64.93(25.98)$ & $67.46(21.36)$ & $65.26(19.92)$ & $66.33(27.58)$ \\
\hline Only utter word, & $77.73(13.7)$ & $84.64(15.24)$ & $68.71(18.04)$ & $74.42(24.87)$ & $79.00(15.28)$ & $74.04(15.79)$ & $72.97(20.09)$ \\
\hline Communicate with & $72.68(13.0)$ & $79.80(16.54)$ & $65.38(15.53)$ & $63.33(19.27)$ & $77.94(14.63)$ & $68.88(13.70)$ & $70.19(16.12)$ \\
\hline$p$-value & 0.01 & 0.005 & 0.37 & 0.09 & 0.002 & 0.05 & 0.35 \\
\hline \multicolumn{8}{|c|}{ Presence of autism in sibb; ling } \\
\hline No & $70.73(17.0)$ & 79.39(19.75) & 64.64(18.67) & $66.47(24.87)$ & 72.01(19.24) & $67.70(18.04)$ & $68.37(23.67)$ \\
\hline Yes & $80.43(9.51)$ & $88.43(6.91)$ & $72.50(13.59)$ & $70.50(16.23)$ & $85.50(13.21)$ & $76.16(11.94)$ & $76.25(18.63)$ \\
\hline$p$-value & 0.07 & 0.00 & 0.19 & 0.61 & 0.03 & 0.14 & 0.14 \\
\hline \multicolumn{8}{|l|}{ Type of family } \\
\hline Nuclear & $71.40(15.6)$ & $77.24(18.67)$ & $66.28(16.68)$ & $66.41(23.4)$ & $72.16(18.73)$ & $68.28(16.76)$ & $69.28(22.95)$ \\
\hline Joint & $71.31(20.0)$ & $77.08(21.74)$ & $61.66(23.05)$ & $67.78(27.5)$ & $75.27(20.56)$ & $68.24(20.96)$ & $67.70(25.04)$ \\
\hline$p$-value & .97 & .96 & .19 & .77 & .39 & .98 & .72 \\
\hline \multicolumn{8}{|l|}{ Mother's education } \\
\hline Illiterate, Primary & $67.27(17.1)$ & $73.26(19.95)$ & $54.44(19.43)$ & $71.66(22.07)$ & 75.00 & $64.07(16.26)$ & $67.12(20.98)$ \\
\hline Higher Secondary & $77.40(12.4)$ & $84.04(11.91)$ & $70.00(16.41)$ & $72.10(23.58)$ & $72.50(11.77)$ & $73.85(15.77)$ & $71.27(20.54)$ \\
\hline Degree/Hons & $70.74(17.2)$ & $76.42(20.15)$ & $65.20(18.48)$ & $65.53(24.67)$ & 75.00 & $67.71(18.14)$ & $68.66(24.11)$ \\
\hline$p$-value & 0.20 & 0.23 & 0.11 & 0.45 & 0.17 & 0.28 & 0.88 \\
\hline \multicolumn{8}{|l|}{ Father's education } \\
\hline Illiterate, Primary & $75.29(12.8)$ & $76.70(12.60)$ & $69.09(18.00)$ & $78.18(17.92)$ & $76.36(17.04)$ & $74.54(15.47)$ & $73.48(17.80)$ \\
\hline Degree/Hons & $71.06(17.0)$ & 77.24(19.85) & $64.85(18.51)$ & $65.83(24.63)$ & 72.64(19.35) & $67.77(17.92)$ & $68.53(23.80)$ \\
\hline$p$-value & 0.42 & 0.93 & 0.46 & 0.10 & 0.53 & 0.22 & 0.50 \\
\hline \multicolumn{8}{|l|}{ Mother's occupation } \\
\hline Housewife, & $72.53(16.9)$ & 77.19(19.34) & $66.71(19.12)$ & $69.25(24.54)$ & $74.16(18.09)$ & $70.04(18.12)$ & $70.02(22.91)$ \\
\hline Teacher, doctor, & $63.87(18.9)$ & 72.61(23.04) & $67.14(17.43)$ & $53.57(22.75)$ & $66.90(24.57)$ & $59.20(18.35)$ & $58.33(26.05)$ \\
\hline Service & $73.29(7.10)$ & $84.15(11.06)$ & 64.64(10.08) & $66.07(19.82)$ & $71.78(18.25)$ & $67.50(8.49)$ & $75.59(19.66)$ \\
\hline$p$-value & 0.08 & 0.22 & 0.09 & 0.02 & 0.27 & 0.03 & 0.05 \\
\hline \multicolumn{8}{|c|}{ Consanguineous marriage } \\
\hline No & $71.32(16.4)$ & 77.63(19.04) & $64.85(18.08)$ & $66.66(24.07)$ & 72.33(19.37) & $67.95(17.63)$ & $68.58(23.19)$ \\
\hline Yes & 71.97(19.9) & $72.99(22.75)$ & $68.21(22.15)$ & $67.50(28.06)$ & $78.57(16.57)$ & 71.42(19.74) & $72.02(26.01)$ \\
\hline$p$-value & 0.89 & 0.39 & 0.51 & 0.90 & 0.24 & 0.48 & 0.60 \\
\hline
\end{tabular}

There was weak negative correlation $(\mathrm{r}=-0.18$; $\mathrm{p}=0.03$ ) between total HRQoL and age of symptom appearance. Age at diagnosis was also weakly correlated $(\mathrm{r}=-0.18 ; \mathrm{p}=0.03)$ with cognitive functioning. Cognitive functioning was strongly correlated with total PedsQL score and its domains ( $r=0.73 ; p=0.00)$ (Table III). To state the important predictors for HRQoL controlling the effect of confounders, linear regression was performed to assess the relationship between HRQoL and independent variables, those found significant in univariate analysis.
The results of the regression indicated the predictors in the model explained $57 \%$ of the variance $(\mathrm{R} 2=.57, \mathrm{~F}=23.05, \mathrm{p}<.001)$.

It was found that fathers who were doctors and engineers by profession ( $\mathrm{t}=2.34, \mathrm{p}=.02)$, child's ability to communicate with words $(\mathrm{t}=2.73$, $\mathrm{p}=.007)$, age of symptom appearance $(\mathrm{t}=-2.71$, $\mathrm{p}=.008)$, and cognitive functioning $(\mathrm{t}=12.28$, $\mathrm{p}<0.000)$ significantly predicted HRQol of ASD children when adjusted for other factors. (Table IV) 
Table III: Relationship of HRQoL and Cognitive functioning with socio-demographic and child factors and Correlation between the HRQoL and Cognitive Functioning scores

\begin{tabular}{|c|c|c|c|}
\hline Domain & $\begin{array}{l}\text { Socio-demographic and } \\
\text { child } \\
\text { factors }\end{array}$ & $\mathrm{r}$ & $\mathrm{p}$-value \\
\hline \multirow{8}{*}{$\begin{array}{l}\text { Mean score of total } \\
\text { health related } \\
\text { quality of life and } \\
\text { sociodemographic } \\
\text { and child } \\
\text { characteristics }\end{array}$} & Age of the child & -.06 & .46 \\
\hline & $\begin{array}{l}\text { Age of symptom } \\
\text { appearance }\end{array}$ & -.18 & .03 \\
\hline & Age at diagnosis & -.08 & .29 \\
\hline & $\begin{array}{l}\text { Maternal age at } \\
\text { pregnancy }\end{array}$ & -.03 & .73 \\
\hline & Father's age at pregnancy & -.04 & .59 \\
\hline & $\begin{array}{l}\text { Number of family } \\
\text { member }\end{array}$ & -.08 & .34 \\
\hline & Schooling & -.05 & .56 \\
\hline & Age of the child & -.09 & .28 \\
\hline \multirow{6}{*}{$\begin{array}{l}\text { Mean score of } \\
\text { cognitive } \\
\text { functioning life and } \\
\text { sociodemographic } \\
\text { and child } \\
\text { characteristics }\end{array}$} & $\begin{array}{l}\text { Age of symptom } \\
\text { appearance }\end{array}$ & -.08 & .32 \\
\hline & Age at diagnosis & -.18 & .03 \\
\hline & $\begin{array}{l}\text { Maternal age at } \\
\text { pregnancy }\end{array}$ & -.02 & .79 \\
\hline & Father's age at pregnancy & .004 & .95 \\
\hline & $\begin{array}{l}\text { Number of family } \\
\text { member }\end{array}$ & .05 & 48 \\
\hline & Schooling & .014 & .86 \\
\hline \multirow{5}{*}{$\begin{array}{l}\text { Mean score of } \\
\text { cognitive } \\
\text { functioning and } \\
\text { Mean scores of } \\
\text { health related } \\
\text { quality of life }\end{array}$} & Mean score of physical & .61 & .00 \\
\hline & Emotional functioning & .56 & .00 \\
\hline & School functioning & .53 & .00 \\
\hline & Psychosocial & .69 & .00 \\
\hline & Total & .73 & .00 \\
\hline
\end{tabular}

Table IV. Linear regression model; best predictors for Pediatric HRQoL

\begin{tabular}{|c|c|c|c|c|}
\hline Model & $\begin{array}{c}\text { Standardized } \\
\text { Coefficients } \\
(\beta) \\
\end{array}$ & Sig. & $\begin{array}{r}95.0^{\circ} \\
\text { of } \\
\text { Lower }\end{array}$ & $\begin{array}{l}\text { C.I } \\
\beta \\
\text { Upper }\end{array}$ \\
\hline Cogni & 0.699 & 12.28 .000 & .42 & .58 \\
\hline Age of sympto & -0.179 & -2.71 .008 & -7.33 & -1.14 \\
\hline $\begin{array}{l}\text { No communication vs only } \\
\text { utter a word }\end{array}$ & 0.161 & 2.73 .007 & 1.76 & 10.94 \\
\hline $\begin{array}{l}\text { Father's Occupation [Service } \\
\text { vs Doctor, Teacher, } \\
\text { Engineer] }\end{array}$ & 0.132 & 2.34 .021 & .77 & 9.24 \\
\hline
\end{tabular}

\section{Discussion}

Results of the present study provide support for our research objectives that was to assess Parents' perception of their children's health related quality of life and cognitive functioning using PedsQL-4.0 Generic code scale (parent proxyreport), to determine the socio- demographic characteristics of the respondents and to determine the association between HRQoL and cognitive functioning with socio-demographic factors.

The average total PedsQL score was highest in physical functioning and the area with lowest score was in emotional functioning. The scenario is similar in the study done by Karen Kuhlthau. ${ }^{2}$ The study revealed male predominance of the disorder, with male 3.4 times more common than female. Same proportion of sex differences was observed in several large scales epidemiological studies conducted in different parts of the world where Autism (including Asperger syndrome) has been found to be more common among boys than girls. ASDs are almost five times more common among boys ( 1 in 54) than among girls (1 in 252), and could be because of genetic differences between the sexes, or that the criteria used to diagnose autism are based on the characteristics of male behaviour. ${ }^{16,17}$

The analysis revealed no statistical significance in mean score differences between male and female. Although all domain scores of HRQoL were higher in female and the cognitive functioning was better in case of male which was supported by other study results. ${ }^{10}$ [fig1]

In the present study, younger age group comprised of the highest proportion of samples.

Parents of younger children consistently reported higher HRQoL scores than parents of older children. The age of the child showed no statistically significant difference between their HRQoL scores which was found similar in another study conducted addressing this issue. ${ }^{2}$

Research has shown that a diagnosis of autism at age two can be reliable, valid, and stable at later childhood.18 More children are being diagnosed at earlier ages - a growing number of them by age three. Still, most children are not diagnosed until after they reach age four.19 Diagnosis is a bit earlier for children with autistic disorder (4 years) than those had ASD (4 years, 5 months), and diagnosis is much later for children with Asperger Disorder (6 years, 3 months) 10 which is analogous to our study finding where the mean age of diagnosis was found to be around 3 years. Age at diagnosis was found to have correlation with cognitive functioning 10 and age of symptom appearance was found correlated with HRQoL. In the present study majority of the children were from nuclear family while the total PedsQL score and cognitive functioning were observed with no difference between them.

The study result revealed no correlation of HRQoL and cognitive functioning with parental 
age which that contradicts several study findings that reported increased parental age at child's birth [for U.S. children in the 1992-2000 birth cohorts] as strongly associated with an increased risk of autism. ${ }^{16}$ Other studies identified maternal age possess more risk than paternal age for the development autism and for their poor quality of life . 19,20

In this study, most of the parents were educated and there were no significant difference between the scores by educational status. This was due to the fact that, children experienced good social and psychosocial health those had their mothers involved in no occupation. On the contrary, the total PedsQL score, physical functioning, social functioning and cognitive functioning was low in those children's mothers were teacher, doctor or engineer. Father's occupation did not show any significant differences with the scores in univariate analysis. This parental occupational relationship with the HRQoL and Cognitive functioning revealed reverse in multiple regression analysis indicating father's occupation significantly related to children's life quality when adjusted for other factors.

Parents' consanguinity was found less frequent in our study than an Arabian study where it was shown to have a significant relationship with autism.21 The study showed total PedsQL and cognitive functioning was better in children whose parents had history of consanguineous marriage. This might be due to the fact that the consanguineous family usually possessed better family functioning than their non consanguineous counterpart that might influence the child's life quality.

The proportion $(\mathrm{n}=10,6.7 \%)$ of affected siblings of autistic children matches with the finding in other study. These children possess better HRQoL and Cognitive functioning though not statistically significant. This may be due to the child gets more learning capacity from his family environment and he gets a company to learn and share properly and the parents can take care of him specially. ${ }^{2}$

In our study a number of children were found to be non-immunized or incompletely immunized may be due to misconception. The mean score was better in those who had history to take incomplete vaccination. The available epidemiologic data suggest no link between childhood vaccination and autism - these data offer no reason why immunization should be avoided or postponed in this regard. ${ }^{3,22}$

If we confer about autism related symptoms less than fifty percent of the children could not communicate verbally and a similar percentage was found to be so in other study. The

children who could communicate verbally showed a better functioning in the total PedsQL, physical functioning and school functioning. However, it was not significant in case of cognitive functioning though they performed a better score in this sector. Whether the children could speak or not their mean duration of schooling was three years. But shockingly there found no relationship in HRQoL and cognitive functioning in children with Autism with duration of schooling. It is suggested that the measurement of HRQoL and cognitive functioning in school-aged children with Autism should be considered for routine assessment in clinical practice, clinical trials, and intervention outcome studies..$^{2,10,15,23}$ This is may be due to the fact that the selected schools might not provide proper level of intervention to these children which is reciprocal to the findings of other studies which suggested that therapies or interventions could improve HRQoL. 2, 10, 15

In this study one third proportion of children had history of taking any other medicine due to other causes who had better functioning in all aspects. This may be because of the effect of the medication to control their behavioral problems, hyperactivity etc. and some medication thought to have regenerative effect on nerves. ${ }^{13}$

In the present study it was found that the children who had better cognitive ability did better with overall HRQoL as there had strong correlation between this two functioning.

This report provided support for other study. ${ }^{2}$ Children with good cognitive functioning could better understand their familial and social coherence, attain improved adaptability, enjoy a higher level communication in their own milieu thus enjoy better HRQoL than children with low cognitive functioning state. ${ }^{10,}{ }^{24}$ Children having good cognitive ability performed better in physical functioning, emotional functioning, social functioning, psychosocial functioning as well as school functioning. 


\section{Limitation of the study:}

There were several limitations in the present study. First, these results represented the collective experience of children and adolescents with ASD who were studying in specialized schools. As such, they might not represent the full range of experience of children with ASD. Secondly, reports of HRQoL were based on parent proxy report, not child self report. Though this was a validated methodology for children, the PedsQL is also commonly administered using child self-report versions. We have chosen only to collect parent report surveys due to the severe cognitive and communication issues faced by a majority of our study sample; most children would not have been able to self-report reliably.9 Finally, results were correlational in nature and causality could not be inferred.

Thus, while we could claim that HRQoL was related to several behavior correlates of ASD, we could not determine whether these behavior correlates caused change in HRQoL or whether some other, unidentified variables were contributing to both.

Conclusion: Autism prevalence rates showing an increasing trend in Bangladesh and globally.

Occupational status of the father, child factors correspond; child's ability to communicate by word, 'age of symptom appearance", and cognitive functioning of ASD children were found related to their quality of life. Thus, it would seem important to design intervention addressing these factors as part of an overall treatment plan ensuring a satisfactory QoL for children with autism.

\section{Acknowledgement}

We acknowledge Directorate General of Health Services for their institutional and administrative support. We are also grateful to the authorities of five specialized schools for their support and to the respondents for their sincere cooperation.

\section{References}

1. Hirtz DG, Wagner A, Filipek PA. Autistic Spectrum Disorders. In: Swiman KF, Asnwal S, Ferriero DM. Editor, Pediatric Neurology: Principles and Practice, Vol-1, Philadelphia; Elsevier; 2006.P.905-35.

2. Kuhlthau K, Orlich F, Hall TA, Sikora D, Kovacs EA, et al. Health-Related Quality of Life in children with autism spectrum disorders: results from the autism treatment network.J Autism Dev Disord. 2010; 40: 721-9.
3. Rahman MM. Autism Spectrum Disorder. J Bangladesh Coll Phys Surg. 2010; 28(3): 143-4. [Editorial]

4. Kose S, Erermis S, Ozturk O, Ozbaran B, Demiral N, Bildik N, Aydin C. Health Related Quality of Life in children with Autism Spectrum Disorders: The clinical and demographic related factors in Turkey.Research in Autism Spectrum Disorders.2013; 7(2): 213-220.

5. Kamp-Becker I, Schröder J, Remschmidt H, Christian Bachmann J. H ealth-related quality of life in adolescents and young adults with high functioning autism-spectrum disorder. GMS Psycho-SocialMedicine 2010, Vol. 7, ISSN 1860-5214

6. Darryn M. Sikora, Parul Vora, Daniel L. Coury and Daniel Rosenberg. Attention- Deficit/Hyperactivity Disorder Symptoms, Adaptive Functioning, and Quality of Life in Children with Autism Spectrum Disorder. Pediatrics 2012; 130; S91, DOI:10.1542/peds.2012-0900G.http://pediatrics. aappublications.org/content/130/Supplement_2/S91. full.html

7. Audrey F. Burgess \& Steven E. Gutstein. Quality of Life for People with Autism: Raising the Standard for Evaluating Successful Outcomes. Child and Adolescent Mental Health Volume 12, No. 2, 2007, pp. 80-86.

8. Potvin M, Snider L, Prelock PA, Dauphinee SW and Kehayia K. Health related quality of life in children with high-functioning autism. Published online 8 November2013;Autism.DOI:10.1177/13623613135 09730.http://aut.sagepub.com/content/early/2013/11/ 07/1362361313509730

9. Shipman D, Sheldrick C, Perrin EC. Quality of Life in Adolescents with Autism Spectrum Disorders: Reliability and validity of Self Reports. J Dev Behav Pediatr 2011; 32(2):85-9.

10. Limbers CA, Heffer R W, Varni J W. Health-Related Quality of Life and Cognitive Functioning from the Perspective of Parents of School-Aged Children with Asperger's Syndrome Utilizing the PedsQL ${ }^{\text {TM.J }}$ of Autism Dev Disord. November 2009; 39 (11): 152941.

11. Exkorn KS.The Autism Sourcebook Everything You Need To Know About Diagnosis, Treatment, Coping, And Healing. Australia:Harpercollins Publishers (Australia) Pty. Ltd. 25 Ryde Road (Po Box 321) Pymble, Nsw 2073; 2005.

12. Kim YS, Leventhal BL, Koh YJ et al. Prevalence of autism spectrum disorders in a total population sample. Am J Psychiatry. 2011; 168(9):904-12.

13. Johnson CP, Myers SM. Identification and evaluation of children with autism spectrum disorders. American Academy of Pediatrics.1 Jul 2009; 120, 1183-1215. 
14. Dosreis S, Weiner CL, Johnson L, Newschaffer CJ. Autism spectrum disorder screening and management practices among general pediatric providers. J Dev Behav Pediatr. 2006; 27(2 suppl): 88-94.

15. Varni JW, Seid M, Kurtin PS.PedsQL 4.0: reliability and validity of the Pediatric Quality of Life Inventory version 4.0 generic core scales in healthy and patient populations. Med Care. 2001 Aug;39(8):800-12.

16. CDC. Prevalence of Autism Spectrum Disorders-Autism and Developmental Disabilities Monitoring Network, 14 Sites, United States, 2008. Surveill Summ, MMWR. March 30, 2012; 61(SS03):1-19.

17. Prevalence of Autism Spectrum Disorders Autism and Developmental Disabilities Monitoring Network, 14 Sites, United States, 2008.

18. Lord C, Risi S, DiLavore PS, Shulman C, Thurm A, Pickles A. Autism from 2 to 9 Years of Age. Arch Gen Psychiatry. June 2006, Vol 63, (6) 694-701.
19. Liu K, Zerubavel N, Bearman P. Social Demographic Change and Autism.Demography, 2010; 47(2):327-43.

20. Al-Salehi SM, Al-Hifthy EH, Ghaziuddin M. Autism in Saudi Arabia: presentation, clinical correlates and comorbidity. Transcult Psychiatry.2009Jun;46(2) :340-7.doi: 10.1177/1363461509105823.

21. King M, Bearman P. Diagnostic Change and the increased prevalence of autism. Int $\mathrm{J}$ Epidemiol. 2009; 38(5): 1224-34.

22. Fombonne E, Zakarian R, Bennett A, Meng L, McLean- Heywood D. Pervasive developmental disorders in Montreal, Quebec, Canada: prevalence and links with immunizations. Pediatrics. 2006; 118(1), e139-50.

23. Marcia A. Testa, Donald C. Simonson, Assessment of Quality-of-Life Outcomes. N Engl J Med. 1996; 334(13):835-40.

24. Myers S. M, Johnson C. P, Management of Children with Autism Spectrum Disorders. Official J of the Am Ac of Paediatrics2007; 120:1162-1175. 